\title{
Study of the feasibility of a rice husk recycling scheme in Japan to produce silica fertilizer for rice plants
}

\author{
Ryoko Sekifuji and Masafumi Tateda*
}

\begin{abstract}
Rice husks are resources that should be recycled in a sustainable way, thus creating a win-win relationship between stakeholders, consumers, and society. Silica is a very valuable material and used for many industrial purposes. A Rice husk contains $20 \%$ of silica by weight, and can therefore be considered a biological silica ore. To recycle rice husks in a sustainable way, the ash produced from burning rice husks must also be used as a resource. In this study, based on the concept that rice husk ash should be recycled as silica fertilizer, we compared the economic feasibility of two recycling systems: Heat recovery from hot water and generation of electricity from hot water. Questionnaires were also conducted regarding farmers' expectations of silica fertilizer made from rice husk ash. We found that the system involving heat recovery from hot water was sustainable; however, generating electricity from hot water was cost-prohibitive. It must be noted that the validity of this result might be limited to Japan, where electricity generation is highly regulated. On the other hand, areas that already struggle to dispose of their rice husks should consider using rice husks to produce energy.
\end{abstract}

Keywords: Rice husks, Silica, Fertilizer, Energy recovery, Recycling

\section{Introduction}

Renewable energy is the key to creating a sustainable society. Biomass is one of many sources of renewable energy. In Japan, since 25 billion $\mathrm{m}^{2}$ of land was covered by forest in 2017 [1], equivalent to $66 \%$ of Japan's entire area, forest timber may be considered a suitable form of renewable energy. However, the long lifespan of trees seriously draws into question the idea of timber being an appropriate renewable energy source. Rice husks, on the other hand, are generated every year and are therefore a suitable form of renewable energy. On the other hand, using rice husks for energy comes with a major drawback. Rice plants accumulate silica, so that rice husks and straws are approximately 20 and 5\% silica, respectively. This implies that rice plants need silica to grow, which is why rice plants absorb amorphous silica that is dissolved in irrigation water. If enough silica is not available to rice plants, they do not grow well and fail to stand straight up in paddy fields. This leads to invasion

\footnotetext{
* Correspondence: tateda@pu-toyama.ac.jp

Department of Environmental Engineering, Toyama Prefectural University, Toyama 939-0398, Japan
}

(c) The Author(s). 2019 Open Access This article is distributed under the terms of the Creative Commons Attribution 4.0 International License (http://creativecommons.org/licenses/by/4.0/), which permits unrestricted use, distribution, and

by insects or causes water from the rice to evaporate during the growing period; in either case, the plants do not produce good rice $[2,3]$. Rice plants need silica to grow healthily. The ash content of a rice husk is about $20 \%$ by weight, which is extremely high compared to other biomass such as poplar (1.0\%) and cedar (0.2\%) [4]. Approximately 20 tons of ash will remain when 100 tons of rice husk are burned for heat recovery.

Dealing with the large amount of remaining ash is extremely difficult and stressful for stakeholders. Therefore, they have preferentially used timber for heat recovery, with rice husks as their last choice. To use rice husks as a renewable energy source, it is essential to find a way to economically recycle the ash generated from burning rice husks [5]. Rice husks can be sustainably used as a fuel for energy recovery only when their ash is used as a resource. The ash is mostly made up of silica, which, if amorphous, has many industrial applications. An optimal condition to produce effectively amorphous silica was investigated in a field-scale furnace [6]. Given that rice plants in Japan require additional silica to grow healthily, silica fertilizer must be applied to paddy fields. 


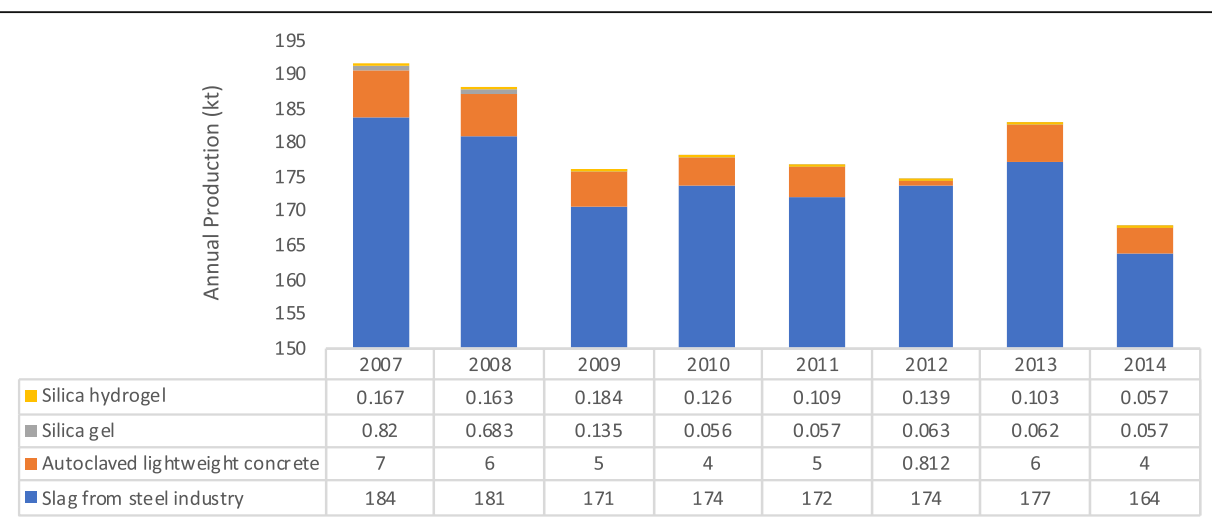

Fig. 1 Annual production of authorized silica fertilizers

Currently, the fertilizer used in Japan is produced by materials from other industries. Figure 1 shows the main sources of silica fertilizers that have been used for rice production $[7,8]$. Slag from the steel industry has mainly been used for this purpose. The main goal of this research is to return silica in rice husks to the original paddy field as a fertilizer, in order to make rice production more environmentally and economically sound. The purpose of this study was to evaluate the feasibility of rice production based on rice husk ash recycling by comparing two schemes: heat recovery and silica fertilizer production. The study was based on a questionnaire method.

\section{Rice plants and silica}

Rice plants need silica for healthy, continuous growth [9]. Although it may not be essential $[3,10]$, a shortage of silica has a tremendous negative effect on rice plants, and its presence benefits the plants. Silica provides rice plants with disease control $[2,10,11]$, resistance to drought $[2,12]$ and salt $[2,13]$, and metal toxicity control $[2,10,14]$.

In Japan, the study of the effects of silica on rice plants began in the late 1930s [15]. The study was conducted in a hydroponic culture and showed that silica was needed to improve crop yields and resistance to pest invasion. However, the results were not confirmed in actual fields because people thought that rice plants would not face a silica deficit there due to the existing abundance of silica in soil. Since continuous cultivation of rice is possible in paddy fields but not in dry-fields, Japan prefers paddy field cultivation for rice because it is a staple crop for Japanese people. Moreover, Japan is a small island and has limited areas for rice production.

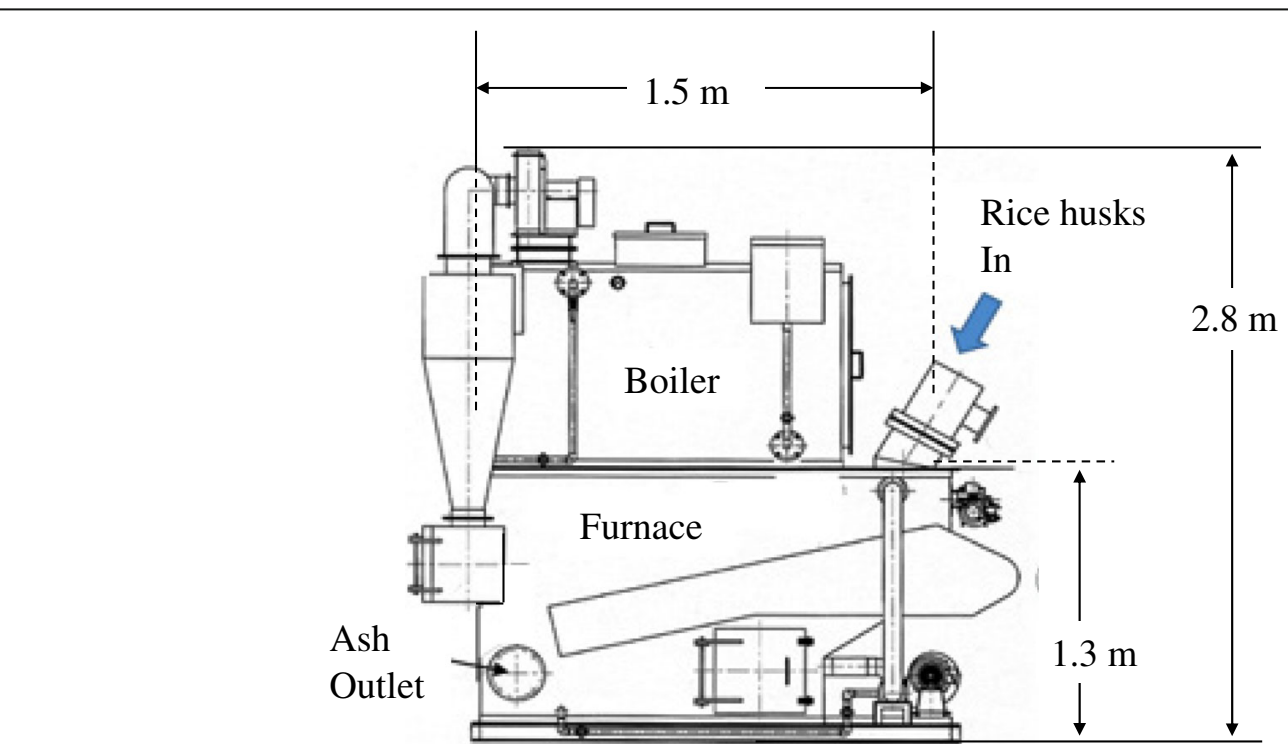

Fig. 2 The Boiler used in this study [6] 


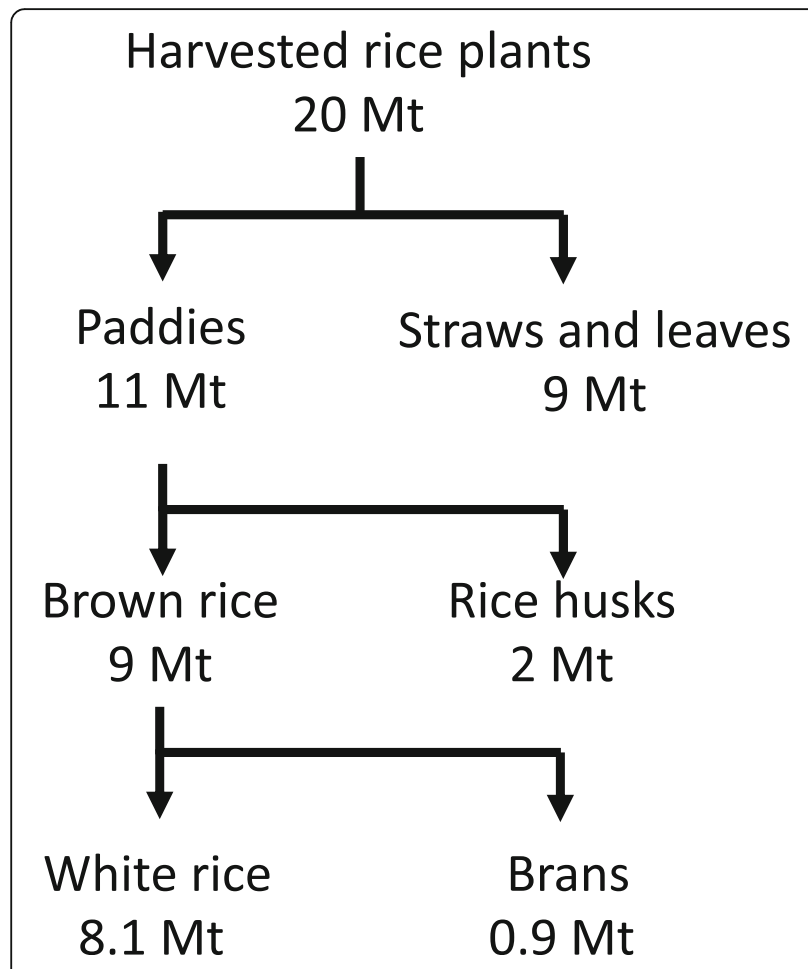

Fig. 3 Distribution of rice plants at each step post-harvest (numbers shown are approximate actual tons)

However, a large volume of irrigation water passes through paddy fields, which flushes away dissolved silica. Moreover, silica is reduced in anaerobic conditions in paddy fields and dissolves into water, where it is also flushed away. Consequently, silica availability became low, causing rice plants to sometimes lose condition and became affected by pests in fall. This phenomenon, called "the fallen condition in fall," became the one of the main topics of agricultural studies in the 1950s, when the Japanese government wanted to increase rice production during the era of food shortage that followed World War II.

The silica taken up by rice plants is amorphous and in a colloidal state in water. The silica in rice husks is therefore also amorphous. To use rice husk ash for fertilizer, it is critical that the silica is in an amorphous state. It is impossible to distinguish amorphous and crystalline silica by visual observation; X-ray diffraction (XRD) analysis is required. The solubility of silica into 1 $\mathrm{N} \mathrm{NaOH}$ is a reliable indicator of the state of silica in the ash [16]. Generally, it can be said that the higher the percentage of solubility is (more than 50\%), the better quality the silica is. Solubility is also expressed by the Silica Activity Index [17]. Many studies have been conducted on how to produce better ash, including how to burn rice husks [18-21]. These studies mainly focused on combustion temperature. Other studies focused on energy recovery from rice husk burning concentrating only on energy production and did not consider the quality of ash [22-26]. A further study investigated using different types of incinerators such as fluidized bed, cyclonic furnace, and rotary kiln to burn rice husks [27]. To make better ash, the formation of carbon black particles in the ash was investigated with the goal of reducing the amount of carbon black particles produced [28]. In the 1980s, researchers assessed the growth of crystalline silica in rice husk ash [29] and the thermal decomposition characteristics of rice husks [30]. Rice husks have many industrial applications including insulators [27, 31, 32],

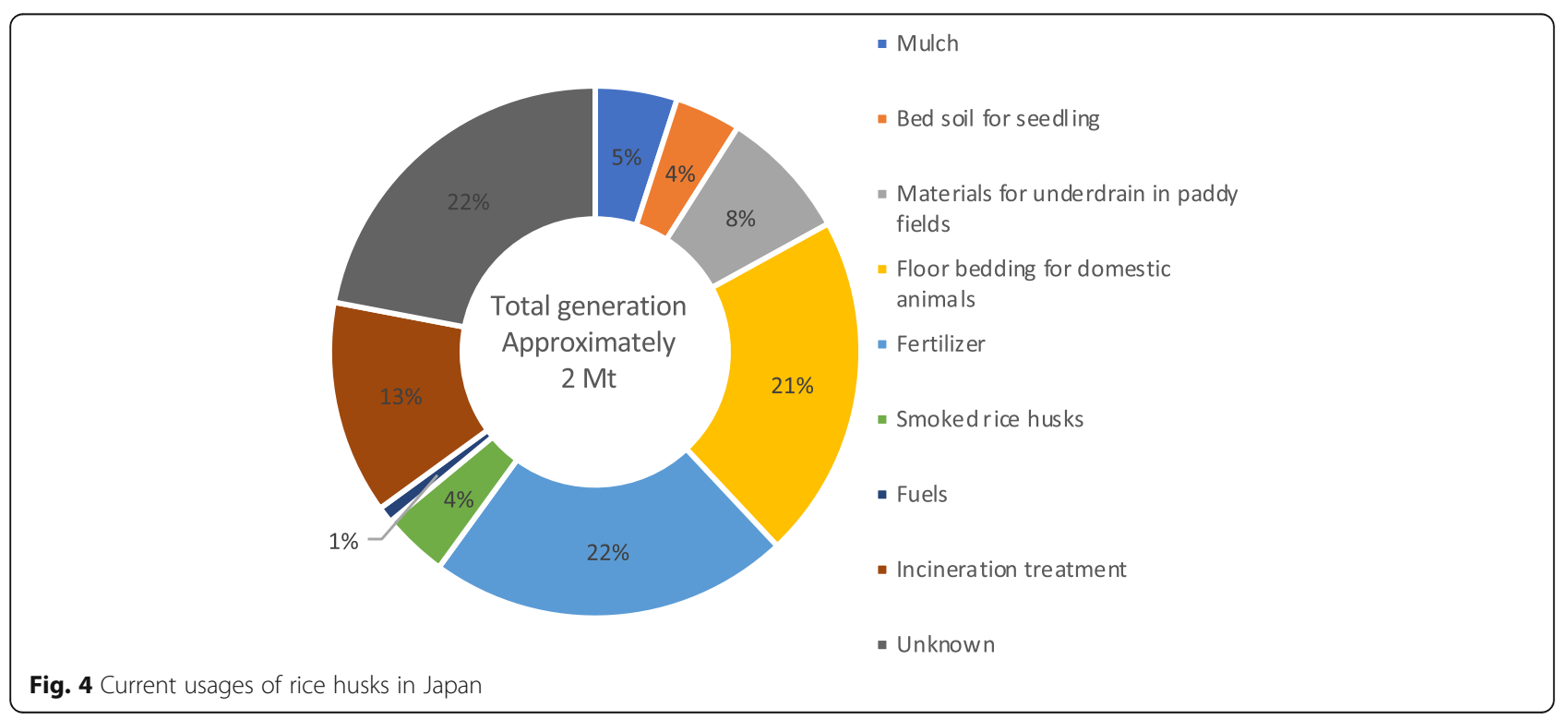




\section{a}

What kinds of effects do you expect silica fertilizer made from rice husks to have on to rice plants?

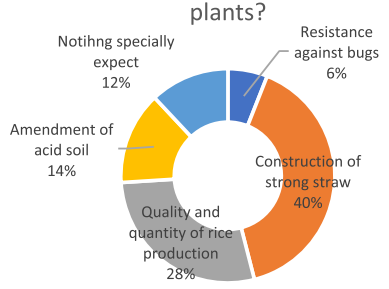

c

What states of fertilizer do you prefer?

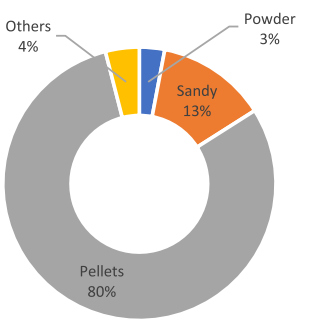

$\mathbf{e}$ How much silica fertilizer would you apply to $100,000 \mathrm{~m}^{2}$ ?

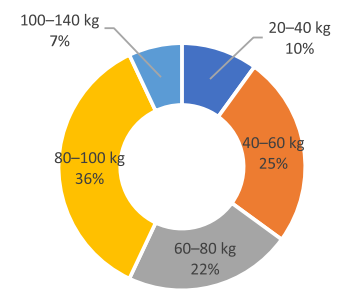

b

What factors influence your purchase of a silica fertilizer?

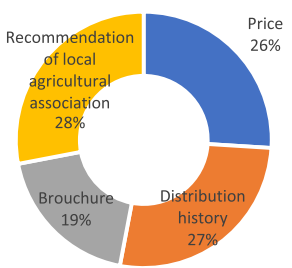

d

What do you expect from silica fertilizer made from rice husks?

Others
$4 \%$

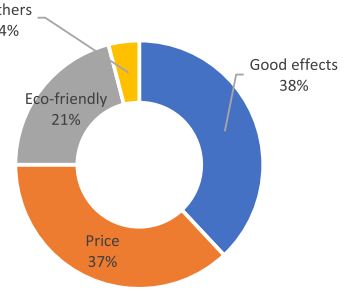

f

How much would you be willing to pay for silica fertilizer made from rice husks for an area of $100,000 \mathrm{~m}^{2}$ ?

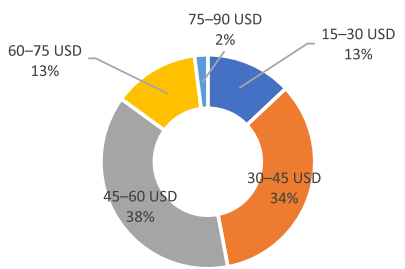

Fig. 5 Results of questionnaire about rice husk silica fertilizers. (a) What kinds of effects do you expect silica fertilizer made from rice husks to have on to rice plants? (b) What factors influence your purchase of a silica fertilizer? (c) What states of fertilizer do you prefer? (d) What do you expect from silica fertilizer made from rice husks? (e) How much silica fertilizer would you apply to 100,000 m²? and (f) How much would you be willing to pay for silica fertilizer made from rice husks for an area of 100,000 $\mathrm{m}^{2}$ ?

lithium battery anodes [31, 33], fuels [27, 31, 34], cement and concrete [27, 35], wastewater adsorbents [31, 36, 37], and fertilizer and soil amendment [5, 31].

\section{Materials and methods}

\section{Research site}

The Local Agriculture Association Imizuno (LAAI) in City Imizu (approximate population: 90,000) in Toyama Prefecture, Japan, was chosen for the study. LAAI sells agricultural products that the members of the association grow under a contract, instead of the members selling their products by themselves. Rice is one of the products sold by LAAI, so rice from various paddies was brought to LAAI for milling. LAAI has three milling facilities: a, b, and c. Facility "a" (LAAIa) was chosen for conducting this research. The LAAI has been spending a high tipping fee for rice husk disposal annually and purchasing silica fertilizers, and spending a high cost for kerosene use for greenhouse operation. The basic concept in this research was that the recycling of rice husks would solve those problems.

\section{Questionnaire on use of rice husk ash as silica fertilizer}

To understand users' expectation of silica fertilizer from rice husks and produce a better silica fertilizer product for users, several questionnaires were sent to the members of LAAI. The questions were as follows: what kinds of effects do you expect silica fertilizer made from rice husks to have on to rice plants? What factors influence your purchase of a silica fertilizer? What states of fertilizer do you prefer? What do you expect from silica fertilizer made from rice husks? How much silica fertilizer would you apply to $100,000 \mathrm{~m}^{2}$ ? How much would you be willing to 


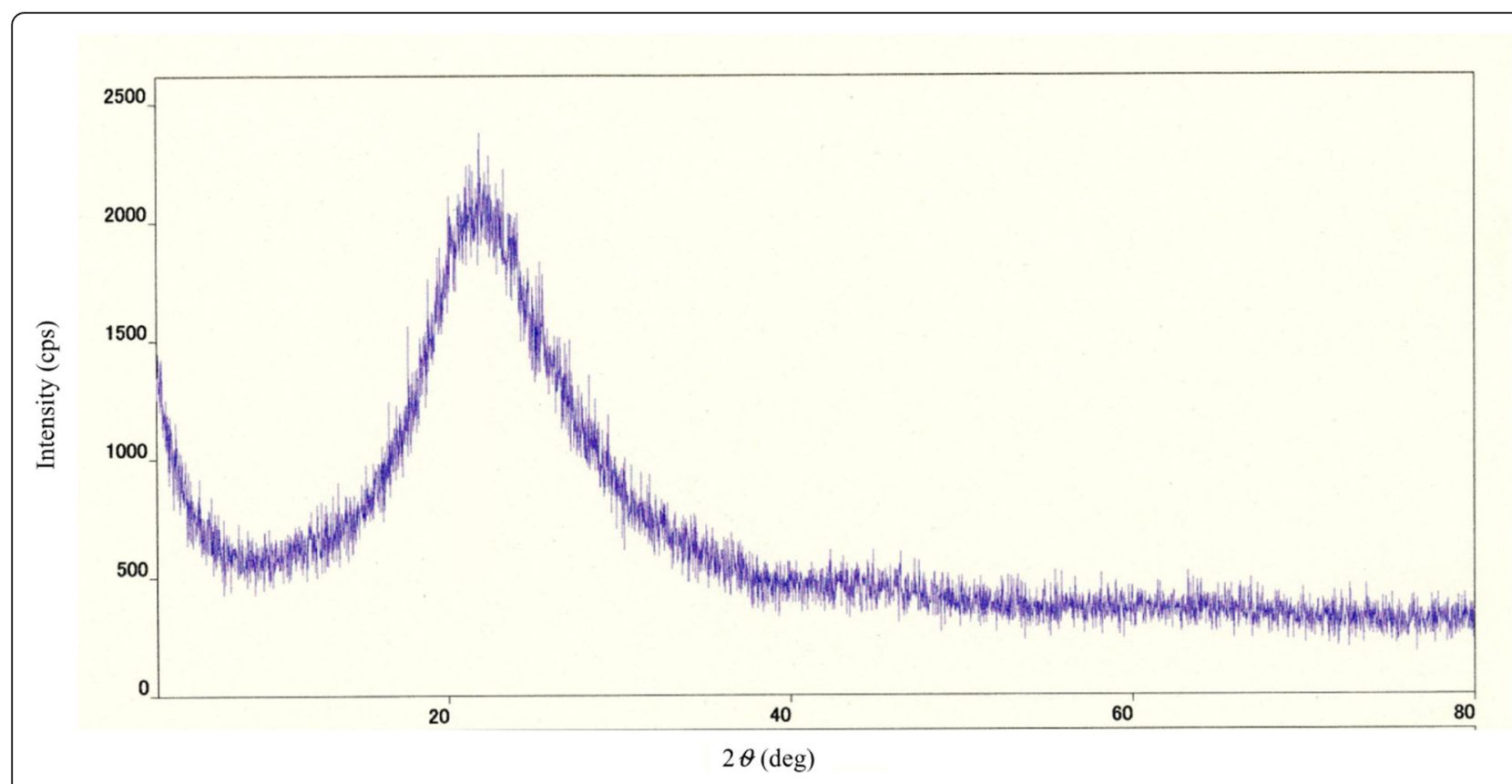

Fig. 6 An X-Ray Diffraction chart of amorphous silica made from rice husks

pay for silica fertilizer made from rice husks for an area of $100,000 \mathrm{~m}^{2}$ ?

\section{Comparing the processes of heat recovery from rice husks}

For energy recovery, two schemes were compared: heat recovery from hot water and electricity generation. The comparison was made in scaled-up model based on data obtained from the current small-scale model.

\section{Measurement and analysis \\ Furnace}

A small-scale furnace, with moving grates and an air blower system, was used to burn the rice husks as shown

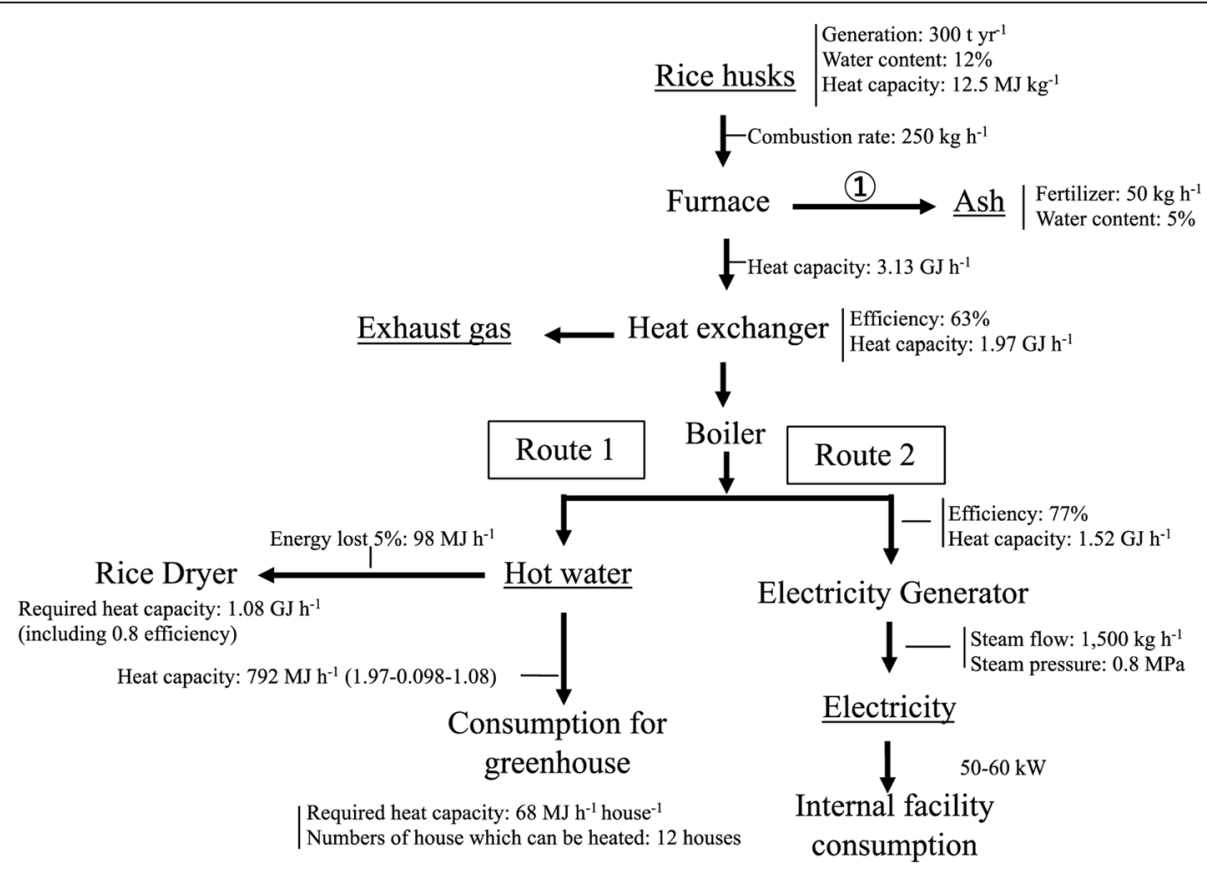

Fig. 7 Two energy recovery schemes based on rice husks 
Table 1 Cost of the ash pelletizing process

\begin{tabular}{lll}
\hline Items & $\begin{array}{l}\text { Annual costs } \\
\left(\text { USD }^{\mathrm{a}}\right)\end{array}$ & Notes \\
\hline Pelletizer & 20,000 & 200,000 USD $(10 \text { depreciation } \mathrm{yr})^{-1}$ \\
Running cost & 12,000 & 1000 USD month \\
Maintenance & 12,000 & 1000 USD month \\
cost & & 0.5 person (35,000 USD person $\left.{ }^{-1}\right)$ \\
Labor cost & 17,500 & \\
Total & 61,500 & \\
\hline
\end{tabular}

$\mathrm{a}_{1}$ USD $=100$ yen

in Fig. 2 [38]. The hourly combustion capacity was 100 $\mathrm{kg}$ of rice husks.

\section{Determination of amorphous state}

XRD analysis was done by Smart Lab (Rigaku) with the conditions of $9 \mathrm{~kW}, \mathrm{Cu}-\mathrm{K} \alpha$, and $2 \theta: 5-80^{\circ}$.

\section{Results and discussion Research site}

Approximately $1.5 \mathrm{kt}$ of rice husks are annually generated at LAAI facilities a-c. The water content of these husks is about $12 \%$. Figure 3 shows the stages of use of a cultivated rice plant and the product division, by weight, at each step [39]. According to the figure, the $1.5 \mathrm{kt}$ of rice husks that come from the LAAI facilities may be the result of over $8 \mathrm{kt}$ of production from the paddies. In Japan, $2 \mathrm{Mt}$. of rice husks are generated annually and used for different purposes (Fig. 4). Floor bedding for domestic animals, compost, and unknown purposes each account for over $20 \%$ of the overall use of rice husks (over $60 \%$ all together). At the LAAI, half of the annual $1.5 \mathrm{kt}$ is used for floor bedding for domestic animals and materials for underdrain in paddy fields, but several hundred thousand USD are also spent to dispose of rice husks. The facility at which this research was conducted annually generates approximately $0.6 \mathrm{kt}$ of rice husks. Although half of those are used for other purposes, such as floor bedding and underdrain materials, those usages are very unstable because the recycling is to some extent forcibly conducted. Therefore, it would be ideal to use all $0.6 \mathrm{kt}$ of rice husks for a more sustainable purpose.

Table 2 Cost of the boiler in Route 1

\begin{tabular}{|c|c|c|}
\hline Items & $\begin{array}{l}\text { Annual costs } \\
\left(\text { USD }^{\mathrm{a}}\right)\end{array}$ & Notes \\
\hline Boiler for hot water & 25,000 & 200,000 USD (8 depreciation yr) \\
\hline Running cost & 12,000 & 1000 USD month ${ }^{-1}$ \\
\hline Maintenance cost & 9600 & 800 USD month ${ }^{-1}$ \\
\hline Labor cost & 35,000 & One person \\
\hline Total & 81,600 & \\
\hline
\end{tabular}

$\mathrm{a}_{1}$ USD $=100$ yen
Table 3 Cost of the boiler in Route 2

\begin{tabular}{lll}
\hline Items & Annual costs $\left(\right.$ USD $\left.^{\mathrm{a}}\right)$ & Notes \\
\hline Boiler for hot water & 25,000 & $\begin{array}{l}200,000 \text { USD } \\
(8 \text { depreciation years })^{-1}\end{array}$ \\
Electric generator & 5700 & $\begin{array}{l}80,000 \text { USD } \\
(14 \text { depreciation years })^{-1}\end{array}$ \\
Running cost & 14,400 & 1200 USD month $^{-1}$ \\
Maintenance cost & 15,000 & 1250 USD month $^{-1}$ \\
Labor cost & 35,000 & One person \\
Total & 95,100 & \\
\hline
\end{tabular}

${ }^{\mathrm{a}_{1}}$ USD $=100$ yen

Questionnaire on use of rice husk ash as silica fertilizer A questionnaire was distributed to the members of the LAAI. The questionnaire was sent to 94 members; 90 were returned (collection percentage: 95.7\%). The results are shown in Fig. 5a-f. According to the results, member farmers expect the silica fertilizer to increase the strength of the rice plants' straw, so that the plants will not be easily bent over by wind (Fig. 5a). Recommendation by a local agricultural association, price, and distribution history mostly influence the members' purchase of silica fertilizer (Fig. 5b). Pellets were the preferred state of silica fertilizer (Fig. 5c) because it can easily be handled, which was very important to the farmers. Powder, on the other hand, was considered very difficult to handle. Farmers' expectations of silica fertilizer made from rice husks were mostly centered on its beneficial effects for rice plants and its price (Fig. $5 \mathrm{~d}$ ). The estimated amount of silica fertilizer required for $100,000 \mathrm{~m}^{2}$ was $80-100 \mathrm{~kg}$ (Fig. 5e). The price that the farmers could pay for silica fertilizer for $100,000 \mathrm{~m}^{2}$ was 30-60 USD (Fig. 5f).

\section{Comparing the processes of heat recovery from rice husks}

The essential condition for heat recovery is that the silica in rice husk ash must be amorphous. Silica exists in two phases at ambient temperature and pressure: amorphous and crystalline. The former is safe, while the latter is a carcinogen and highly hazardous. Originally, the silica in rice husks is amorphous. Because rice plants need silica for healthy growth, they absorb silica from the irrigation water, which is amorphous and dissolved in the water in a colloidal state. Figure 6 shows the result of our XRD analysis. The XRD diagram proves that the silica in rice husk ash from the furnace was not crystallized, but amorphous. This amorphous state means that the silica from rice husk ash could be used for other purposes.

The following operating conditions were utilized. The annual rice husk generation was $0.6 \mathrm{kt}$ at LAAIa, half of which is recycled. The current recycling methods, however, are not stable. We anticipate that the amount of 
Table 4 Cost savings from reducing kerosene consumption in Route 1

\begin{tabular}{lll}
\hline Processes & Cost saved (USD) & Notes \\
\hline $\begin{array}{l}\text { For rice } \\
\text { drying }\end{array}$ & $61,875=25 \mathrm{~L} \mathrm{~h}^{-1} \cdot 12.5 \mathrm{~h} \mathrm{~d}^{-1} \cdot 220 \mathrm{~d} \mathrm{yr}^{-1} \cdot \$ 0.9 \mathrm{~L}^{-1}$ & $25 \mathrm{~L} \mathrm{~h}^{-1}:$ kerosene consumption \\
& & $12.5 \mathrm{~h} \mathrm{~d}^{-1}:$ dairy operation hours \\
& $220 \mathrm{~d} \mathrm{yr}^{-1}:$ yearly operation day \\
For & $0.9 \mathrm{USD} \mathrm{L}^{-1}:$ kerosene price \\
greenhouses & Heating period: November-March \\
& $32,076=11 \mathrm{~L} \mathrm{~m}^{-2} \mathrm{yr}^{-1} \cdot 3240 \mathrm{~m}^{2} \cdot 0.9 \mathrm{~L}^{-1}$ & $11 \mathrm{~L} \mathrm{~m}^{-2} \mathrm{yr}^{-1}:$ kerosene consumption \\
& & $3240 \mathrm{~m}^{2}: 12{\text { greenhouses }\left(270 \mathrm{~m}^{2} \text { house }\right.}^{-1}$ ) \\
& $0.90 \mathrm{USD}^{-1}:$ kerosene price \\
\hline
\end{tabular}

recycling will shrink in the future; therefore, the amount used for incineration is flexible and can be estimated to be much larger. Hence, a burning rate of $250 \mathrm{~kg} \mathrm{~h}^{-1}$ was set as the standard burning rate of rice husks. It was also reported that $250 \mathrm{~kg} \mathrm{~h}^{-1}$ rate is an economically feasible capacity [40]. Assuming six working hours per day and $220 \mathrm{~d}$ per year, the amount of husks produced overall would equate to a burning rate of $250 \mathrm{~kg} \mathrm{~h}^{-1}$. Because rice husks have a calorific value of $12.5 \mathrm{MJ} \mathrm{kg}^{-1}$, normal burning at $250 \mathrm{~kg} \mathrm{~h}^{-1}$ leads to $3.13 \mathrm{GJ} \mathrm{h}^{-1}$ of energy. Figure 7 shows the process flows from inputting rice husks into the furnace to the heat recovery stages. The hot water available after the boiler was either consumed by the greenhouse or used to produce electricity for on-site use.

After the rice husks were burned, the ash was generated. This point is indicated by the number (1) in Fig. 7 . The ash generated was approximately $20 \%$ of the weight of the rice husks, or $50 \mathrm{~kg} \mathrm{~h}^{-1}$. Solubility is an indicator of the quality of the silica in rice husk ash [18]. Higher solubility indicates better quality ash, while lower solubility indicates more crystalline silica. Heat capacity of $3.13 \mathrm{GJ} \mathrm{h}^{-1}$ was sent to the heat exchanger, which has $63 \%$ efficiency according to its operating history. From there, $1.97 \mathrm{GJ} \mathrm{h}^{-1}$ of heat was sent to the boiler. From the boiler, two routes were compared in this study.

In Route 1, hot water produced from the boiler was used directly for two processes: as a heat source for drying rice and to distribute heat to greenhouses. Based on kerosene consumption, which is how heat is currently supplied, the rice dryer required a heat capacity of $1.08 \mathrm{GJ} \mathrm{h}^{-1}$, and each greenhouse required $68 \mathrm{MJ} \mathrm{h}^{-1}$ [5]. The required heat to dry rice was calculated based on $25 \mathrm{~L} \mathrm{~h}^{-1}$ of kerosene consumption. The amount for the greenhouse was obtained using the coefficient of $22.8 \mathrm{KJ} \mathrm{h}^{-1}{ }^{\circ} \mathrm{C}^{-1} \mathrm{~m}^{-2}$,

Table 5 Cost savings from reducing electricity consumption in Route 2

\begin{tabular}{|c|c|c|}
\hline Processes & Cost saved (USD) & Remarks \\
\hline $\begin{array}{l}\text { For internal } \\
\text { facility use }\end{array}$ & $\begin{array}{l}9438=55 \mathrm{~kW} \cdot 6 \mathrm{~h} \mathrm{~d}^{-1} \\
.220 \mathrm{~d} \mathrm{yr^{-1 }} \cdot 0.13 \mathrm{USD} \mathrm{kWh}^{-1}\end{array}$ & $\begin{array}{l}55 \mathrm{~kW} \text { : mean electricity } \\
\text { generation } \\
6 \mathrm{~h} \text { : rice husk burning dairy } \\
\text { operation } \\
220{\mathrm{~d} \mathrm{yr}^{-1} \text { : yearly operation }} \text { day } \\
0.13 \mathrm{USD} \mathrm{kWh}^{-1}\end{array}$ \\
\hline
\end{tabular}

assuming the presence of curtains or insulators (35.5 KJ $\mathrm{h}^{-1}{ }^{\circ} \mathrm{C}^{-1} \mathrm{~m}^{-2}$ without curtains or insulators). This coefficient was derived from the equation described in the previous report [5]. The heat capacity sent to the greenhouses after the rice dryer would be $792 \mathrm{MJ} \mathrm{h}^{-1}$, meaning that 12 greenhouses could be heated.

In Route 2, hot water produced from the boiler was used to generate electricity. The heat capacity was 1.52 GJ $\mathrm{h}^{-1}$ with a turbine efficiency of $77 \%$. Assuming a steam flow and steam pressure of $1500 \mathrm{~kg} \mathrm{~h}^{-1}$ and 0.8 $\mathrm{MPa}$, respectively, $50-60 \mathrm{~kW}$ of electricity would be generated. The electricity was consumed by the facility.

To evaluate the sustainability and feasibility of the two routes (Routes 1 and 2), their operating costs were compared. The two processes both produce ash; using this ash for silica fertilizer is the basic concept of rice husk recycling, and according to the results shown in Fig. 5c, the ash must be pelletized. The cost for pelletizing ash is shown in Table 1. Expenses for operating the boiler used in Route 1 are shown in Table 2, while the expenses for the boiler in Route 2 are in Table 3.

To evaluate the feasibility and sustainability of these methods, we compared the savings from reducing the currently energy sources with the cost of the proposed method. In Route 1, the costs saved would result from reducing kerosene consumption in the rice drying process and greenhouses; this is summarized in Table 4. In Route 2, savings would come from reducing the amount of electricity that the facility was required to purchase (Table 5). The advantage of this recycling scheme is that it allows the ash generated from burning rice husks to be sold as fertilizer. As shown in Fig. 7, since the combustion rate was $250 \mathrm{~kg} \mathrm{~h}^{-1}$, ash would be generated at a rate of $50 \mathrm{~kg} \mathrm{~h}^{-1}(20 \%$ of rice husks by

Table 6 Revenue from the sale of silica fertilizer

\begin{tabular}{|c|c|c|}
\hline Item & Income (USD) & Remarks \\
\hline $\begin{array}{l}\text { Ash fertilizer } \\
\text { sale }\end{array}$ & $\begin{array}{l}46,200 \mathrm{USD}^{-}=50 \mathrm{~kg} \mathrm{~h}^{-1} \cdot 6 \mathrm{~h} \mathrm{~d}^{-1} \\
\cdot 220 \mathrm{~d} \mathrm{yr}^{-1} \cdot 0.7 \mathrm{USD} \mathrm{kg}^{-1}\end{array}$ & 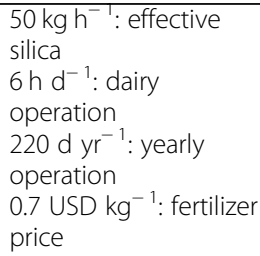 \\
\hline
\end{tabular}


Table 7 Expenses and costs saved in Routes 1 and 2 (USD)

\begin{tabular}{llll}
\hline & Items & Route 1 & Route 2 \\
\hline Expenses & Pelletizing & 61,500 & 61,500 \\
& ash & & \\
& Boiler & 81,600 & 95,100 \\
operation & & - \\
Costs & Rice drying & 61,875 & - \\
saved & Greenhouse & 32,076 & 9438 \\
& heating & & \\
& Electricity & & 46,200 \\
& consumption & & \\
& Fertilizer sale & 46,200 & $-100,962(9438+46,200)-(61,500+95,100)$ \\
& Profits & $-2949(61,875+32,076+46,200)-(61,500+81,600)$ &
\end{tabular}

weight would become ash). However, the price of the fertilizer produced must meet farmers' expectations. According to Figs. 5e and 4f, farmers expected to use 80$100 \mathrm{~kg}$ of fertilizer for a $10,000 \mathrm{~m}^{2}$ paddy field, for which they would pay $\$ 45-60$ USD. Therefore, the price of the silica fertilizer would be set at $\$ 0.70 \mathrm{USD} \mathrm{kg}^{-1}$, which is $80 \%$ of the price of the silica fertilizer that is currently used. The sale of the fertilizer was guaranteed in this case because farmers were members of the LAAI. Table 6 shows revenue from sale of the fertilizer.

The expenses and savings for Routes 1 and 2 are summarized in Table 7. For Route 1, the profit was negative, making the system unsustainable. However, a negative balance can easily become positive if more rice husks are burned each year, thereby increasing fertilizer sales. If $350 \mathrm{t} \mathrm{yr}^{-1}$ were burned, instead of 300 , the net profit becomes -177 USD; however, if 375 or $400 \mathrm{t}$ were burned annually, the net profit jumps to 2595 and 6845 USD, respectively. Increasing the quantity of husks burned is feasible, because, as mentioned earlier, other methods to recycle rice husks - such as mulching and floor bedding - are not stable pathways. Hence, Route 1 can be evaluated as a sustainable, feasible scheme for recycling rice husks. On the other hand, Route 2 incurred a net profit of $-119,442$ USD. This sizable deficit would be impossible to fill with other income sources. Even if all $600 \mathrm{t}$ of rice husks were burned to produce silica fertilizer, the expected income of 84,000 USD would still result in a 35,442 USD deficit.

\section{Conclusions}

In this study, we evaluated physicochemical and economic feasibility of improving agricultural processes by recycling rice husks, which contain amorphous silica. Amorphous silica effectively promotes the healthy growth of rice plants. We found that using the heat from burning rice husks to heat water was sustainable and feasible. On the other hand, burning rice husks to generate electricity was not sustainable; its high operational costs and the low sales price of electricity meant that this pathway was not economically viable. However, we only examined a Japanese case study. For villages in developing countries without electricity and with rice as a main agricultural product, generating electricity by burning rice husks is an excellent option. Sustainability and feasibility evaluations must therefore be conducted on a place-by-place basis. Rice husks are no longer waste but are a sustainable resource. Our findings may mean that rice husk ash is listed as an authorized silica fertilizer by the Ministry of Agriculture, Forestry and Fisheries.

\section{Authors' contributions \\ The present study was carried out in collaboration between both the authors. RS designed, performed, analyzed, interpreted, and drafted manuscript. MT provided technical support and revised the manuscript, and also supervised the research. Both the authors read and approved the final manuscript.}

\section{Competing interests}

The authors declare that they have no competing interests.

\section{Publisher's Note}

Springer Nature remains neutral with regard to jurisdictional claims in published maps and institutional affiliations.

Received: 25 September 2018 Accepted: 4 December 2018

Published online: 18 April 2019

\section{References}

1. MAFF. Forestry Statistics Handbook 2017. Tokyo: Ministry of Agriculture, Forestry and Fisheries; 2017. http://www.rinya.maff.go.jp/j/kikaku/toukei/ attach/pdf/youran_mokuzi2017-8.pdf [in Japanese]

2. Ma JF, Takahashi E. Functions of silicon in plant growth. In: Soil, fertilizer, and plant silicon research in Japan. Amsterdam: Elsevier; 2002. p. 73-106.

3. Ma JF, Yamaji N. Silicon uptake and accumulation in higher plants. Trends Plant Sci. 2006;11:392-7.

4. The Japan Institute of Energy. Biomass handbook. Tokyo: Ohmsha Publisher; 2002 [in Japanese].

5. Tateda M. Production and effectiveness of amorphous silica fertilizer from rice husks using a sustainable local energy system. J Sci Res Rep. 2016:9:1-12.

6. Tateda M, Sekifuji R, Yasui M, Yamazaki A. Case study: technical considerations to optimize rice husk burning in a boiler to retain a high solubility of the silica in rice husk ash. J Sci Res Rep. 2016;11:1-11.

7. AAFS. Handbook of Fertilizers Statistics 2011/2012. Tokyo: Association of Agriculture and Forestry Statistics; 2013 [in Japanese]. 
8. AAFS. Handbook of Fertilizers Statistics 2015/2016. Tokyo: Association of Agriculture and Forestry Statistics; 2017 [in Japanese].

9. Meena VD, Dotaniya ML, Coumar V, Rajendiran S, Ajay KS, et al. A case for silicon fertilization to improve crop yields in tropical soils. P Natl A Sci India B. 2014;84:505-18.

10. Guntzer F, Keller C, Meunier JD. Benefits of plant silicon for crops: a review. Agron Sustain Dev. 2012;32:201-13.

11. Jeer M, Suman K, Maheswari TU, Voleti SR, Padmakumari AP. Rice husk ash and imidazole application enhances silicon availability to rice plants and reduces yellow stem borer damage. Field Crop Res. 2018;224:60-6.

12. Zhu YX, Gong HJ. Beneficial effects of silicon on salt and drought tolerance in plants. Agron Sustain Dev. 2014;34:455-72.

13. Abdel-Haliem MEF, Hegazy HS, Hassan NS, Naguib DM. Effect of silica ions and nano silica on rice plants under salinity stress. Ecol Eng. 2017;99:282-9.

14. Li RY, Stroud JL, Ma JF, McGrath SP, Zhao FJ. Mitigation of arsenic accumulation in rice with water management and silicon fertilization. Environ Sci Technol. 2009;43:3778-83.

15. Takahashi E. What is Silica for Crops? Tokyo: Rural Culture Association; 2007 [in Japanese].

16. Tateda M, Sekifuji R, Yasui M, Yamazaki A. A proposal for measuring solubility of the silica in rice husk ash. J Sci Res Rep. 2016:11:1-11.

17. Deshmukh P, Bhatt J, Peshwe D, Pathak S. Determination of silica activity index and XRD, SEM and EDS studies of amorphous $\mathrm{SiO}_{2}$ extracted from rice husk ash. T Indian I Metals. 2012;65:63-70.

18. Chandrasekhar S, Satyanarayana KG, Pramada PN, Raghavan P, Gupta TN. Processing, properties and applications of reactive silica from rice husk - an overview. J Mater Sci. 2003;38:3159-68.

19. Xiong L, Sekiya EH, Sujaridworakun P, Wada S, Saito K. Burning temperature dependence of rice husk ashes in structure and property. J Met Mat Min. 2009;19:95-9.

20. Martinez JD, Pineda T, Lopez JP, Betancur M. Assessment of the rice husk lean-combustion in a bubbling fluidized bed for the production of amorphous silica-rich ash. Energy. 2011;36:3846-54.

21. Fernandes IJ, Calheiro D, Kieling AG, Moraes CAM, Rocha TLAC, Brehm FA, et al. Characterization of rice husk ash produced using different biomass combustion techniques for energy. Fuel. 2016;165:351-9.

22. Chungsangunsit T, Gheewala SH, Patumsawad S. Environmental assessment of electricity production from rice husk: a case study in Thailand. Int Energ J. 2005;6:3-47-55

23. Ramirez JJ, Martinez JD, Petro SL. Basic design of a fluidized bed gasifier for rice husk on a pilot scale. Lat Am Appl Res. 2007;37:299-306.

24. Prasara-A J, Grant T. Comparative life cycle assessment of uses of rice husk for energy purposes. Int J Life Cycle Assess. 2011;16:493-502.

25. Lim JS, Manan ZA, Alwi SRW, Hashim H. A review on utilisation of biomass from rice industry as a source of renewable energy. Renew Sust Energ Rev. 2012;16:3084-94.

26. Bhattacharyya SC. Viability of off-grid electricity supply using rice husk: a case study from South Asia. Biomass Bioenergy. 2014;68:44-54.

27. Soltani N, Bahrami A, Pech-Canul MI, Gonzalez LA. Review on the physicochemical treatments of rice husk for production of advanced materials. Chem Eng J. 2015;264:899-935.

28. Krishnarao RV, Subrahmanyam J, Kumar TJ. Studies on the formation of black particles in rice husk silica ash. J Eur Ceram Soc. 2001;21:99-104.

29. Ibrahim DM, Helmy M. Crystallite growth of rice husk ash silica. Thermochim Acta. 1981:45:79-85.

30. James J, Rao MS. Silica from rice husk through thermal decomposition. Thermochim Acta. 1986;97:329-36.

31. Pode R. Potential applications of rice husk ash waste from rice husk biomass power plant. Renew Sust Energ Rev. 2016;53:1468-85.

32. Sekifuji $R$, Tateda M. Comparison of processes for producing better rice husk silica produced from a field-scale incinerator. J Sci Res Rep. 2017;17:1-8.

33. Liu N, Huo K, McDowell MT, Zhao J, Cui Y. Rice husks as a sustainable source of nanostructured silicon for high performance Li-ion battery anodes. Sci Rep-UK. 2013;3:1919.

34. Shimizu H, Kanno A, Nishiyama Y. Physical properties of rice hull as the fuel. Jpn Soc Agri Machin. 1978;39:477-81 [in Japanese]

35. Rukzon S, Chindaprasirt P, Mahachai R. Effect of grinding on chemical and physical properties of rice husk ash. Int J Min Met Mater. 2009;16:242-7.

36. Kumar A, Singha S, Dasgupta D, Datta S, Mandal T. Simultaneous recovery of silica and treatment of rice mill wastewater using rice husk ash: an economic approach. Ecol Eng. 2015;84:29-37.
37. Mor S, Chhoden K, Ravindra K. Application of agro-waste rice husk ash for the removal of phosphate from the wastewater. J Clean Prod. 2016;129:673-80,

38. Sekifuji R, Le Van C, Tateda M. Case study of fire flame resistance improvement of a plywood board coated with paint containing added rice husk amorphous silica. J Sci Res Rep. 2017;15:1-9.

39. RCA. Utilization of Rice Husks. Tokyo: Rural Culture Association; 2012 [in Japanese].

40. Jain A, Rao TR, Sambi SS, Grover PD. Energy and chemicals from rice husk Biomass Bioenergy. 1994;7:285-9.

\section{Ready to submit your research? Choose BMC and benefit from:}

- fast, convenient online submission

- thorough peer review by experienced researchers in your field

- rapid publication on acceptance

- support for research data, including large and complex data types

- gold Open Access which fosters wider collaboration and increased citations

- maximum visibility for your research: over $100 \mathrm{M}$ website views per year

At BMC, research is always in progress.

Learn more biomedcentral.com/submissions 